\title{
Efeito do Zen Shiatsu na Redução do Nível de Dorsolombalgias em Profissionais de Enfermagem em Ambiente Hospitalar
}

\author{
Nicola, Anair Lazzari; Eberhardt, Thaís Dresch; Lopes, Sandra Mara Silvério; \\ Hofstätter, Lili Marlene; Silva, Edson Antonio Alves da; Boleta-Ceranto, Daniela de \\ C. F. \\ Universidade Estadual do Oeste do Paraná — anairln@yahoo.com.br
}

Introdução: É impossível humanizar a atenção se não for discutida a dimensão humana e redução do sofrimento de "quem cuida". a dorsalgia/lombalgia são os distúrbios osteomusculares mais prevalentes e incapacitantes entre trabalhadores da enfermagem em ambiente hospitalar. o Zen shiatsu (técnica de massagem que consiste na aplicação de pressão dos dedos e palma da mão sobre meridianos do corpo utilizados pela acupuntura e movimentação das articulações) é apontado na literatura como uma possibilidade terapêutica para a redução da dor. Objetivo: Analisar $o$ efeito do Zen shiatsu sobre o nível de dorsolombalgias em profissionais de enfermagem. Métodos: Estudo experimental, longitudinal. a população alvo foi constituída por trabalhadores de enfermagem de um hospital escola do estado do Paraná que sentiam dorsolombagia. $103(23,36 \%)$ trabalhadores manifestaram sentir dorsolombalgia. Foram incluídos no estudo profissionais com idade superior a 18 anos, que sentissem este tipo de dor de qualquer origem, aguda ou crônica, que não fizessem uso de medicamentos analgésicos e/ou anti-inflamatórios diariamente. Foram excluídos os que apresentaram lesões na região dorsal, febre, pós-operatório recente, fraturas recentes na coluna, mulheres no primeiro trimestre de gestação, consumo de bebidas alcoólicas e refeição recente. Aplicou-se um delineamento estatístico completamente casualizado para a seleção de 20 voluntários para compor a amostra, que receberam uma sessão da intervenção em decúbito ventral, com pressão nos Meridianos da Bexiga e Vaso Governador (nas costas) e ao redor das escápulas, em sequência prédeterminada. para mensurar os níveis de dor, utilizou-se a escala visual analógica (EVA), na qual o voluntário preencheu a nota de sua dor nos sete dias antes do tratamento (momento antes), imediatamente após o tratamento (momento pós-imediato) e sete dias após (momento após), sendo que zero significa ausência de dor e dez a máxima dor sentida. o estudo foi aprovado pelo Comitê de Ética em Pesquisa institucional (Parecer no 125/2013) e os indivíduos assinaram um termo de consentimento livre e esclarecido. Resultados: 17 indivíduos preencheram os critérios de inclusão e aceitaram participar da pesquisa. a média de dor no momento antes foi de 5,28, reduzindo para 1,56 no momento pós-imediato e 1,83 no momento após. ao aplicar Teste de Spearman pareado para comparar as médias dos momentos antes e pós-imediato, obteve-se pvalor de 1,39 x 10-7; ao comparar as médias dos momentos antes e após, obteve-se p-valor de 1,76 x 10-5. Ou seja, como estes $p$-valores são < 0,05, aceita-se a hipótese de diferença entre as médias. Conclusão: Conclui-se que a terapia Zen shiatsu é eficaz na redução dos níveis de dorsolombalgias quando aplicada em profissionais de enfermagem e este efeito se mantém por sete dias. As práticas integrativas e complementares podem favorecer o cuidado humanizado em saúde, também quando aplicadas aos trabalhadores de enfermagem.

Nicola, Anair Lazzari; Eberhardt, Thaís Dresch; Lopes, Sandra Mara Silvério; Hofstätter, Lili Marlene; Silva, Edson Antonio Alves da; Boleta-Ceranto, Daniela de C. F.. Efeito do Zen Shiatsu na Redução do Nível de Dorsolombalgias em Profissionais de Enfermagem em Ambiente Hospitalar. In: Anais do Congresso Internacional de Humanidades \& Humanização em Saúde [= Blucher Medical Proceedings, num.2, vol.1]. São Paulo: Editora Blucher, 2014. ISSN 2357-7282 DOI $10.5151 /$ medpro-cihhs-10547 